- Endocarditis

- Failed Mitral Valve Surgery

- Primary Mitral Regurgitation: Anatomy, Imaging, Decision Making

- Real Mitral Valve Cases

- Rheumatic Valve Disease

- Systolic Anterior Motion

- TAVR

- Tricuspid Valve Disease

- Tough Decision Making

- Valve Regurgitation in Heart Failure

\section{Honored Lecturers:}

- William C. Roberts, MD, MACC

Register, Reserve Housing, and View Program at http:// www.cardiosource.org/HeartValve2014

\section{AATS Focus on Thoracic Surgery: Novel Technologies in Lung Cancer}

November 21-22, 2014

Renaissance Boston Waterfront Hotel

Boston, MA

Lung cancer is the second most common malignancy in the Western world and the most common cause of cancerrelated death. Recent innovations in diagnosis, staging, and management of early stage and locally advanced nonsmall cell lung cancer have changed the paradigm for surgical management of lung cancer patients. A virtual explosion of technological development has enabled widespread use of minimally invasive approaches that current and future thoracic surgeons must embrace to improve the care of patients with lung cancer.

Join us in Boston once again as the AATS highlights these recent developments in its 2014 "Focus on Thoracic Surgery" program, which will focus on Novel Technologies in Lung Cancer. The faculty includes internationally recognized experts in lung cancer and application of new technology for its surgical management. We look forward to seeing you in Boston!

\section{PROGRAM COMMITTEE MEMBERS}

G. Alec Patterson, Program Director

Washington University School of Medicine

David J. Sugarbaker, Program Director

Brigham and Women's Hospital

Thomas A. D'Amico

Duke University Medical Center

Shaf Keshavjee

University of Toronto

James D. Luketich

University of Pittsburgh Medical Center

Bryan F. Meyers

Washington University School of Medicine

Scott J. Swanson

Brigham and Women's Hospital/Harvard Medical School

Dana Farber Cancer Institute

Course Highlights:

- Imaging and Staging

- Surgical Alternatives

- Simulation, Education and Training

- Institutional Impact of New Technology, featuring Larry Kaiser of Temple University

- Optimal Management of Lung Metastases

- Credentialing/Efficiencies

- Intraoperative Management

- Advanced Minimally Invasive Techniques

For more details and to register, please visit: http://aats.org/ lungcancer.

\section{New in 2014-Save the Date}

\section{5th Annual Meeting}

April 25-29, 2015

Washington State Convention Center

Seattle, Washington

\section{The American Association for Thoracic Surgery Journals}

\section{Seminars in Thoracic and Cardiovascular Surgery}

Seminars in Thoracic and Cardiovascular Surgery Editors, Dr Harvey Pass and Dr Todd Rosengart, would like to call your attention to several articles of interest in the current issue of the journal. "The 1000th VAD, the Great Rivalry, and the Grand Experiment of the Texas Medical Center," a commentary on Dr O.H. "Bud" Frazier's 1000th VAD implantation has been co-published in the JTCVS, Texas Heart Institute Journal, and Seminars. 